\title{
Valuation of default-sensitive claims under imperfect information (Publisher's Erratum)
}

\section{Delia Coculescu • Hélyette Geman • Monique Jeanblanc}

Published online: 28 August 2009

(C) Springer-Verlag 2009

\section{Erratum to: Finance Stoch (2008) 12: 195-218 \\ DOI 10.1007/s00780-007-0060-6}

Due to errors in the typesetting process, some parts of this article were rendered incorrectly in Finance and Stochastics 12(2): 195-218 (2008). The incorrect parts and their correct versions are given here.

(1) On page 199 , the formula

$$
\begin{aligned}
d Y_{t} & =\mu\left(Y_{t}, t\right) d t+\sigma\left(Y_{t}, t\right) d B_{t}+s\left(Y_{t}, t\right) d B_{t}^{\prime} \\
& =\mu\left(Y_{t}, t\right) d t+\sigma_{1}\left(Y_{t}, t\right) d B_{t},
\end{aligned}
$$

The online version of the original article can be found under doi:10.1007/s00780-007-0060-6.

D. Coculescu $(\bowtie)$

Department of Mathematics, ETH, Rämistrasse 101, 8092 Zürich, Switzerland

e-mail: Delia.Coculescu@math.ethz.ch

H. Geman

Birkbeck University of London, Malet Street, London WC1E 7HX, UK

e-mail: h.geman@bbk.ac.uk

\section{Jeanblanc}

Equipe d'Analyse et Probabilités, Université d'Evry Val d'Essonne, rue du Père Jarlan, 91025 Evry Cedex, France

e-mail: monique.jeanblanc@univ-evry.fr

M. Jeanblanc

Europlace Institute of Finance, Paris, France 
should read

$$
\begin{aligned}
d Y_{t} & =\mu\left(Y_{t}, t\right) d t+\sigma\left(Y_{t}, t\right) d B_{t}+s\left(Y_{t}, t\right) d B_{t}^{\prime} \\
& =\mu\left(Y_{t}, t\right) d t+\sigma_{1}\left(Y_{t}, t\right) d \beta_{t},
\end{aligned}
$$

(2) On page 200, after Proposition 3.1, the passage

Proof If $M$ is an $\left(\mathcal{F}_{t}\right)$-local martingale, there exist an $\left(\mathcal{F}_{t}\right)$-predictable process and a constant $m$ such that $M_{t}=m+\int_{0}^{t} h_{u} d B_{u}$. Since the process $\beta$ is a $\left(\mathcal{G}_{t}\right)$ Brownian motion, $M$ is a $\left(\mathcal{G}_{t}\right)$-local martingale.

should read

Proof If $M$ is an $\left(\mathcal{F}_{t}\right)$-local martingale, there exist an $\left(\mathcal{F}_{t}\right)$-predictable process and a constant $m$ such that $M_{t}=m+\int_{0}^{t} h_{u} d \beta_{u}$. Since the process $\beta$ is a $\left(\mathcal{G}_{t}\right)$ Brownian motion, $M$ is a $\left(\mathcal{G}_{t}\right)$-local martingale.

(3) On page 200 , the formula

$$
\begin{aligned}
M_{t} & =\int_{0}^{t} \frac{\sigma_{1}\left(Y_{u}, u\right)}{\sigma\left(Y_{u}, u\right)+\eta\left(Y_{u}, u\right)} d B_{u}, \\
N_{t} & =\int_{0}^{t} \frac{\sigma_{1}\left(Y_{u}, u\right)}{\sigma\left(Y_{u}, u\right)+\eta\left(Y_{u}, u\right)} d D_{u} .
\end{aligned}
$$

should read

$$
\begin{aligned}
M_{t} & =\int_{0}^{t} \frac{\sigma_{1}\left(Y_{u}, u\right)}{\sigma\left(Y_{u}, u\right)+\eta\left(Y_{u}, u\right)} d \beta_{u}, \\
N_{t} & =\int_{0}^{t} \frac{\sigma_{1}\left(Y_{u}, u\right)}{\sigma\left(Y_{u}, u\right)+\eta\left(Y_{u}, u\right)} d D_{u} .
\end{aligned}
$$

(4) On page 210 , the passage

We choose a constant default barrier $b \in\left(0, x_{0}\right)$ and suppose for the observation process the form

$$
d Y_{t}=r Y_{t} d t+\sigma_{1} Y_{t} d B_{t}, \quad Y_{0}=x_{0},
$$

where $\sigma_{1}=\sqrt{\sigma^{2}+s^{2}}$ and $\beta_{t}=\frac{\sigma B_{t}+s B_{t}^{\prime}}{\sigma_{1}}$.

should read

We choose a constant default barrier $b \in\left(0, x_{0}\right)$ and suppose for the observation process the form

$$
d Y_{t}=r Y_{t} d t+\sigma_{1} Y_{t} d \beta_{t}, \quad Y_{0}=x_{0},
$$

where $\sigma_{1}=\sqrt{\sigma^{2}+s^{2}}$ and $\beta_{t}=\frac{\sigma B_{t}+s B_{t}^{\prime}}{\sigma_{1}}$. 
(5) On page 214, the passage

We choose to define the observation process as

$$
d Y_{t}=\lambda\left(\theta-Y_{t}\right) d t+\sigma_{1} d B_{t}, \quad Y_{0}=x_{0},
$$

with $\sigma_{1}=\sqrt{\sigma^{2}+s^{2}}$ and $\beta_{t}=\left(\sigma B_{t}+s B_{t}^{\prime}\right) / \sigma_{1}$. The processes defined in Remark 3.6 take here the particular forms

$$
\begin{aligned}
& M_{t}^{\prime}=\frac{\sigma \sigma_{1}}{\sigma+\eta} \int_{0}^{t} e^{\lambda u} d B_{u}, \\
& N_{t}^{\prime}=\frac{\sigma \eta}{\sigma+\eta} \int_{0}^{t} e^{\lambda u} d B_{u}+\frac{\sigma s}{\sigma+\eta} \int_{0}^{t} e^{\lambda u} d B_{u}^{\prime}
\end{aligned}
$$

with $\eta=s^{2} / \sigma$.

should read

We choose to define the observation process as

$$
d Y_{t}=\lambda\left(\theta-Y_{t}\right) d t+\sigma_{1} d \beta_{t}, \quad Y_{0}=x_{0},
$$

with $\sigma_{1}=\sqrt{\sigma^{2}+s^{2}}$ and $\beta_{t}=\left(\sigma B_{t}+s B_{t}^{\prime}\right) / \sigma_{1}$. The processes defined in Remark 3.6 take here the particular forms

$$
\begin{aligned}
& M_{t}^{\prime}=\frac{\sigma \sigma_{1}}{\sigma+\eta} \int_{0}^{t} e^{\lambda u} d \beta_{u}, \\
& N_{t}^{\prime}=\frac{\sigma \eta}{\sigma+\eta} \int_{0}^{t} e^{\lambda u} d B_{u}+\frac{\sigma s}{\sigma+\eta} \int_{0}^{t} e^{\lambda u} d B_{u}^{\prime}
\end{aligned}
$$

with $\eta=s^{2} / \sigma$.

(6) On page 216 , the formula

$$
d Y_{t}=\mu d t+\sigma_{1} d B_{t},
$$

should read

$$
d Y_{t}=\mu d t+\sigma_{1} d \beta_{t},
$$

